\title{
Use of Stents in Correction of Outflow Disorders from the Main Pancreatic Duct in Patients with Pancreonecrosis
}

\section{Darvin Vladimir Vasilyevich ${ }^{1 *}$, Ilkanich Andrey Yanoshevich ${ }^{2}$, Bubovich Elena Vladimirovna ${ }^{3}$, Voronin Yuri Sergeevich ${ }^{4}$ and Loginov Evgeny Vladimirovich ${ }^{4}$}

${ }^{1}$ Professor, Doctor of Medical Sciences, Surgut State University, Surgut District Clinical Hospital, Russia

${ }^{2}$ Associate Professor, Doctor of Medical Sciences, Surgut State University, Surgut

District Clinical Hospital, Russia

${ }^{3}$ Associate Professor, Candidate of Medical Sciences, Surgut State University, Surgut

District Clinical Hospital, Russia

${ }^{4}$ Candidate of Medical Sciences, Surgut State University, Surgut District Clinical

Hospital, Russia

*Corresponding Author: Darvin Vladimir Vasilyevich, Professor, Doctor of Medical Sciences, Surgut State University, Surgut District Clinical Hospital, Russia.
Received: September 17, 2021

Published: October 22, 2021

(C) All rights are reserved by Darvin Vladimir Vasilyevich., et al.

\begin{abstract}
In acute severe pancreatitis, the progression of pancreatic necrosis and the surrounding fatty tissue is based on an increase in pressure in the main pancreatic duct, and therefore. restoration of outflow from the preserved pancreas by endoscopic intraduodenal correction can be an effective prevention of the progression of the pathological process in the gland itself and its transition to parapancreatic fiber. We have developed and introduced into clinical practice a "long" plastic perforated pancreatic stent of variable diameter. The stenting of the main pancreatic duct was performed according to the classical technique after performing choledochal papillosphincterotomy and papillosphincterotomy of the main pancreatic duct. A comparative analysis of the treatment results of two homogeneous groups of patients with pancreatic necrosis (the main one, in which endoscopic intraduodenal transpupillary correction was performed - 39 and the control one, in which this technology was not used - 52) showed that endoscopic intraduodenal correction of the outflow of secretions through the main pancreatic duct, contributes to a decrease in mortality (23.1\% to $8.5 \%$ ) and a decrease in the frequency of local and general life-threatening complications (from $84.6 \%$ to $17.0 \%$ ).
\end{abstract}

Keywords: Pancreatitis; Mortality; Pancreatic Duct

\section{Introduction}

In the structure of patients with acute abdominal surgical pathology, the proportion of patients with acute pancreatitis (AP) is currently $10-12 \%[1,2]$. The overall mortality rate in patients with acute pancreatitis has not changed significantly over the past few decades and ranges from 5-7\%, while the mortality rate among patients with pancreatic necrosis or pancreonecrosis (PN) without differentiation of the form reaches $23-26 \%$ [1-6]. 
From our point of view, a possible reserve for a reliable improvement in the immediate results of treatment of patients with $\mathrm{PN}$ is the search for diagnostic methods for early objective diagnosis of anatomical and morphological destructive changes of the pancreas and parapancreatic tissues, followed by an objective assessment of the configuration of necrosis, and based on this - in determining the optimal invasive techniques for preventing the progression of pancreatic necrosis and destructive parapancreatitis [3,5]. One of such possible therapeutic methods may be endoscopic intraduodenal correction (EIDC) of a violation of the outflow of pancreatic secretions through the main pancreatic duct, which includes endoscopic papillosphincterotomy (EPST) of the choledochus, EPST of the main pancreatic duct (MPD) (virsungotomy), stenting of the MPD, nasopancreatic drainage. To date, the objectively proven prerequisites for the possible effectiveness of these treatment methods for correcting the outflow of pancreatic juice from the remaining preserved pancreatic tissue can be considered the effectiveness of MPD stenting for the prevention of postmanipulatory acute pancreatitis [6-8]. In addition, duodenoscopy also corrects other pathologies (neoplasms, ulcers, parasites, for example, opisthorchiasis invasion is a common cause of LPD pathology in a number of endemic regions of Russia), which can affect the outflow of pancreatic secretions. Acute inflammatory and infiltrative changes in the pancreatic tissue with the involvement of MPD in the pathological process disrupt the drainage function of the LPD with the possible development of its complete block. In the known schemes of the pathogenesis of $\mathrm{OP}$, an increase in pressure in the ductal system of the pancreas (pancreas) occupies a leading position and leads to the development of autolysis and necrosis of both the gland itself and the surrounding adipose tissue.

In connection with the above, the crucial role of normalization of the outflow of pancreatic secretions to prevent the progression of the pathological process in pancreatic necrosis becomes understandable $[7,8,10]$ However, in the existing scientific literature, there are not enough provisions confirming the concept of the role of violation of the outflow of pancreatic secretions due to compression of the MPD by inflammatory-infiltrative changes in the parenchyma of the gland and parapancreatic infiltrates. There is also no necessary clinical experience in using decompression of the pancreatic duct in pancreatic necrosis, respectively, there are no practical recommendations for correcting violations of the outflow of pancreatic secretions in PN [7-9].

\section{The Purpose of the Study}

Introduction into clinical practice and analyze the effects of transduodenal transpapillary drainage interventions on the immediate results of treatment of patients with pancreatic necrosis.

\section{Material and Methods}

The analysis of modern literature has shown that in different periods of time such methods of improving the outflow of pancreatic secretions in acute pancreatitis as EPST, removal of the pinched stone of the BDS ampoule, dissection of the cicatricial stricture of the LPD ampoule, active aspiration of pancreatic secretions, interventions for tumor strictures in the LPD area, stenting of the main pancreatic duct with short plastic stents, nasopancreatic drainage, as well as the use of intraductal administration of various drugs were used [7-9]. But these methods have not been widely used in practice until today $[4,7]$.

Considering that in patients with PN, the main cause of the progression of the destructive process and its transition to retroperitoneal tissue with the development of systemic complications is a violation of the outflow of pancreatic secretions from the preserved functioning areas of the pancreatic parenchyma due to the involvement of the main pancreatic duct in the pathological process and its compression by an inflammatory infiltrate of the parenchyma. We implemented and analyzed the effect of early decompression of the MPD in transverse PN localized in the head of the pancreas or body (with the preservation of the parenchyma, located distally), for the prevention of the progression of the pathological process and the frequency of complications and deaths. We proceeded from the position that the restoration of the outflow from the preserved part of the pancreas by EIDC is an effective prevention of the progression of the pathological process in the gland itself and its transition to parapancreatic fiber. The possible prospects of this direction in the treatment of severe PN is confirmed by the fact that the effectiveness of stenting of the Virsung duct as a measure of prevention of postmanipulatory pancreatitis is proven $[4,7]$.

To implement this task, the indications were determined and the technology for performing endoscopic papillosphincterotomy of the choledochus, endoscopic papillosphincterotomy of the main pancreatic duct, stenting of the MPD was developed. For this purpose, a long plastic perforated pancreatic stent of variable diameter 7x5 Fr and a biliary stent of a new design with additional bili-

Citation: Darvin Vladimir Vasilyevich., et al. "Use of Stents in Correction of Outflow Disorders from the Main Pancreatic Duct in Patients with Pancreonecrosis". Acta Scientific Gastrointestinal Disorders 4.11 (2021): 22-26. 
ary fixators, perforation holes and a cone-shaped ductal end were developed and introduced into clinical practice (Figure 1).

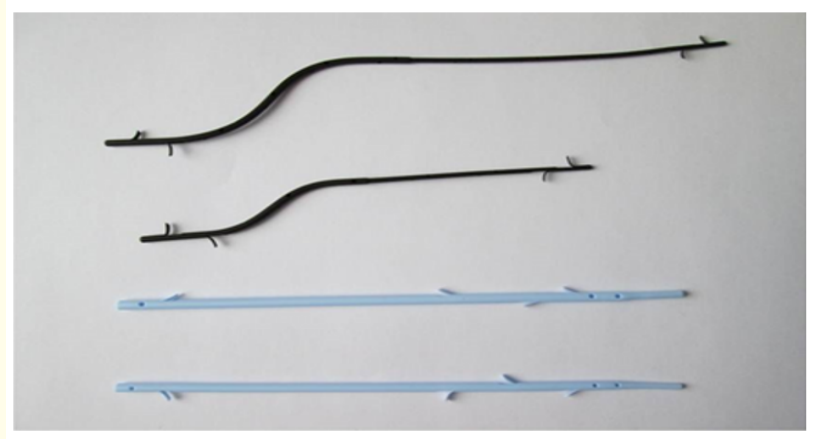

Figure 1: Pancreatic perforated stents with variable diameter $7 \times 5$ Fr made with PTFE (black colour) and biliar stents made with PE (blue colour) diameter 8.5 Fr with cone-shaped ending and extra biliar locks and perforations.

The group studied in this direction included 99 patients with acute severe pancreatitis. Depending on the strategy of invasive treatment used, all patients were divided into two groups - the main and the control group. The main group included 47 patients with aseptic PN who underwent endoscopic intraduodenal correction (EIDC) of a violation of the outflow of pancreatic secretions. The comparison group included 52 patients without the use of EIDC violations of the outflow of pancreatic secretions. The patients of both groups underwent a standard diagnostic and therapeutic algorithm: the study of complaints, anamnesis, objective examination data, special laboratory and instrumental research methods, to determine the severity of the condition, the severity criteria were used according to two systems: APACHE II and J. Ranson. The configuration of pancreatic necrosis was determined using an objective method of investigation-computed tomography with bolus contrast.

\section{Results}

There were no statistically significant differences between the two groups in the severity of the general condition and the local pathological process and the configuration of pancreonecrosis according to computed tomography with bolus contrast ( $p>0.05$ ). In the main group, in addition to the standard treatment algorithm, the methods of EIDC of violation of the outflow of pancreatic se- cretions were performed: endoscopic papillosphincterotomy of the choledochus, endoscopic papillosphincterotomy of the main pancreatic duct, stenting of the main pancreatic duct. Stenting of the main pancreatic duct was performed according to the classical method after performing a choledochal papillosphincterotomy and a papillosphincterotomy of the main pancreatic duct. The pancreatic stent was inserted under endoscopic and X-ray television control using a pusher catheter along an X-ray contrast nitinol conductor with a hydrophilic coating with a diameter of 0.025 inches installed in the main pancreatic duct, after which the conductor and pusher were removed and the outflow of pancreatic secretions was visually monitored. This technique was performed on average for $3 \pm 0.3$ days from the onset of the disease (or for $2 \pm 0.1$ days from the moment of hospitalization). The average standing time of the stents was $79 \pm 16.3$ days.

The available pancreatic stents are intended for stenting in chronic pancreatitis with impaired pancreatic outflow and virsungoectasia - the stents have a single diameter throughout, which does not correspond to the anatomy of the main pancreatic duct. In order to optimize the technique of setting and improving the drainage of the pancreatic duct, we have developed stents for patients with pancreatic necrosis - a pancreatic perforated stent of variable diameter 7x5 Fr made of polytetrafluoroethylene.

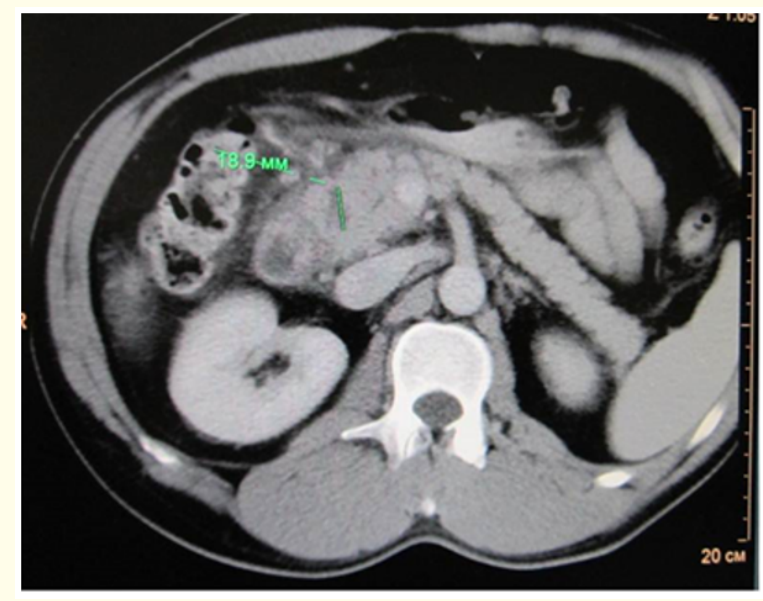

Figure 2: CT with intravenous contrast in a patient with pancreonecrosis of the glandular head before stenting.

According to CT data, there are multiple hypodensive focuses up to $19 \mathrm{~mm}$ in the head, parapancreatic and paraduodenal infiltration of retroperitoneal tissue. 


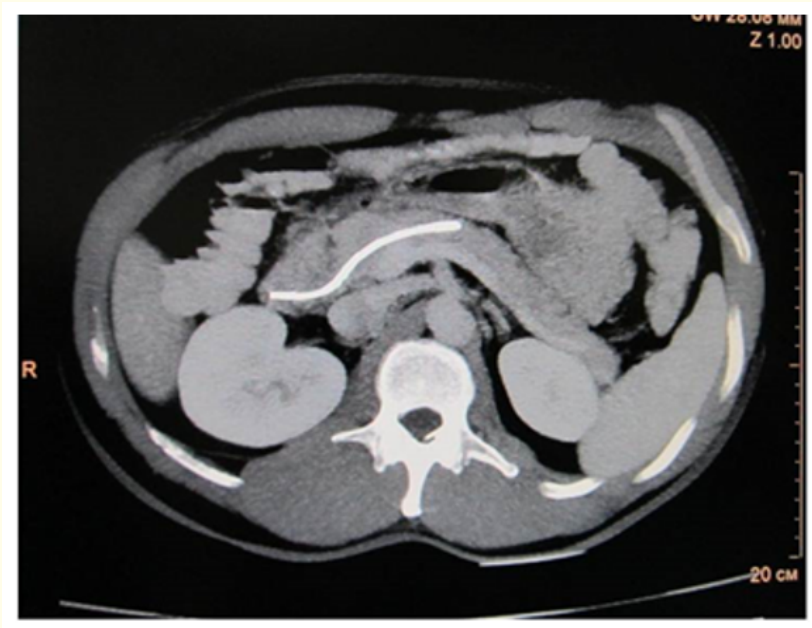

Figure 3: CT with intravenous contrast 8 days after stenting of the main pancreatic duct with a long perforated plastic stent. According to CT data, positive dynamics: a decrease in hypodensive foci in the head of the pancreas, a decrease in parapancreatic and paraduodenal cellular tissue.

In the main group, 39 patients (83.0\%) recovered without parapancreatic complications, 4 (8.5\%) recovered showed the formation of acute fluid accumulations in the parapancreatic fiber ( 2 underwent drainage under ultrasound control, 2 were treated without subsequent invasive interventions). 4 patients died in this group (mortality rate of 8.5\%): 3 had the development of severe complications associated with the progression of pancreatitis (retroperitoneal phlegmons, sepsis, as well as complications from the cardiovascular and respiratory systems) and 1-the cause of death was pulmonary embolism against the background of an improvement in the course of acute pancreatitis.

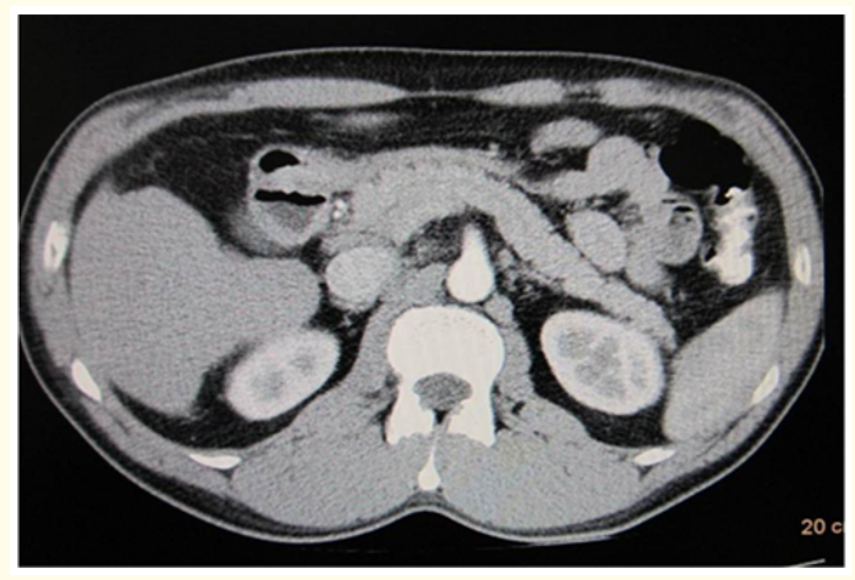

Figure 4: Stent was removed after 3 months. CT with intravenous contrast on the $2^{\text {nd }}$ day after stent removal. Normal pancreas, except for calcinate in the head of the gland.

In the comparison group of 52 patients who underwent a standard diagnostic and therapeutic algorithm, according to national clinical recommendations, without the use of endoscopic intraduodenal correction of pancreatic secretion outflow disorders. The formation of acute fluid accumulations was noted in 14 (26.9\%) patients ( 8 were drained minimally invasively, 6 were treated conservatively). Infected pancreatic necrosis, destructive parapancreatitis occurred in 30 patients (57.7\%). All of them underwent minimally invasive surgical interventions: 5 had drainage under ultrasound control, 25 had drainage from mini-accesses. 12 (23.1\%) patients died in the comparison group. Dynamic of blood reports is represented in table below (Table 1).

\begin{tabular}{|l|c|c|c|c|c|}
\hline & Day 1, x10 $/ \%$ & Day 3, x10 $/ \%$ & Day 5, x10 $/ \%$ & Day 7, x10 $/ \%$ & Day $\mathbf{1 4}, \mathbf{x} \mathbf{1 0} / \mathbf{\%}$ \\
\hline Main group & $14.5 \pm 7.0 / 28 \pm 5$ & $12.7 \pm 2.5 / 30 \pm 4$ & $11.7 \pm 3.7 / 28 \pm 3$ & $10.5 \pm 2.0 / 18 \pm 3$ & $8.4 \pm 2.0 / 8 \pm 2$ \\
\hline Control group & $14.0 \pm 6.2 / 26 \pm 5$ & $13.1 \pm 3.5 / 30 \pm 6$ & $15.4 \pm 6.8 / 34 \pm 6$ & $14.3 \pm 3.2 / 30 \pm 4$ & $12.8 \pm 4.0 / 14 \pm 3$ \\
\hline p-value & $>0.05$ & $>0.05$ & $<0.05$ & $<0.05$ & $<0.05$ \\
\hline
\end{tabular}

Table 1: Dynamic of blood reports - leukocites/neutrophil. 


\section{Conclusions}

- Endoscopic intraduodenal correction of the outflow from the LPD of the pancreas is indicated in patients with massive necrosis of the head and body of the pancreas in the presence of an intact pancreatic parenchyma located proximal to the necrosis zone in the early period (the first 3 days from the moment of the disease), while preference should be given to stenting with a long perforated stent, which provides the best opportunities for correcting intraluminal hypertension.

- Endoscopic intraduodenal correction aimed at improving the drainage function of the pancreatic ductal system is a pathogenetically justified technique, when performed according to proven indications, depending on the configuration of pancreatic necrosis, in the early stages (the first 72 hours from the onset of the disease), it reduces mortality $(23.1 \%$ to $8.5 \%)$ and reduces the frequency of local and general life-threatening complications (from $84.6 \%$ to $17.0 \%$ ), which allows us to recommend this technique for practical use in severe PN.

- Limitations of using describle technique are total pancreatic necrosis, and also later than 72 hours from the beginning of the disease.

\section{Bibliography}

1. Galperin E I., et al. "Diagnosis and surgical treatment of pancreatic necrosis". Surgery 3 (2003): 55-59.

2. Darvin VV., et al. "Minimally invasive technologies in the treatment of acute pancreatitis". Pirogov Russian Journal of Surgery 1 (2009): 29-32.

3. Gostischev VK and Glushko VA. "Pancreatic necrosis and its complications, basic principles of surgical tactics". Surgery 3 (2003): 50-54.

4. Darvin VV., et al. "Severe acute pancreatitis: risk factors of unfavorable outcome and the ability to eliminate them". Journal of Annals of Surgical Hepatology 23.2 (2018): 76-83.

5. Prudkov M I., et al. "Minimally invasive surgery of necrotizing pancreatitis. A manual for doctors". Yekaterinburg (2001): 42.

6. Beger HG., et al. "Natural course of acute pancreatitis". World Journal of Gastrointestinal Surgery 2 (1997): 130-135.
7. Loginov EV., et al. "Stenting of the main pancreatic duct in patients with pancreatic necrosis". Almanac of the A.V. Vishnevsky Institute of Surgery 1 (2017): 128-129.

8. Malyarchuk VI., et al. "Diseases of the major duodenal papilla: a Monograph". Publishing house "Cameron" (2004): 16-17.

9. Mumladze R B., et al. "New aspects of treatment of acute pancreatitis". Fund Of S. Stolyarova (2002): 119-121.

10. Nesterenko Yu A., et al. "Diagnosis and treatment of destructive pancreatitis". $2^{\text {nd }}$ ed.: BINOM-PRESS (2004): 304.

\section{Volume 4 Issue 11 November 2021 \\ (C) All rights are reserved by Darvin Vladimir Vasilyevich., et al.}

